\title{
O Ministério Público Brasileiro Enquanto Instituição de Police Oversight: Controle Externo da Atividade Policial, Direitos Humanos e o Conceito de Investigação Criminal Efetiva
}

\begin{abstract}
Thiago Pinheiro Corrêa
Procurador da República. Especialista em Direto aplicado ao Ministério Público Federal pela Escola Superior do Ministério Público da União. Mestre em Direito pela Universidade Católica de Brasília. http://lattes.cnpq.br/5583573720705102. thiagocorrea25@gmail.com

\section{Nilton Carlos de Almeida Coutinho}

Procurador do Estado de São Paulo em exercício na Procuradoria do Estado de São Paulo em Brasília. Especialista em Planejamento e Gestão Municipal pela FCT/Unesp. Especialista em Direito Público pelo complexo jurídico Damásio de Jesus. Especialista em Direito Penal e Processual Penal pela Escola Superior do Ministério Público de São Paulo. Mestre em Direito pelo Cesumar/PR. Doutor em Direito Político e Econômico pela Universidade Presbiteriana Mackenzie. Professor junto à Escola Superior da Procuradoria Geral do Estado de São Paulo. Pesquisador na área do direito público, direitos fundamentais e proteção da dignidade da pessoa humana. http://lattes.cnpq.br/4999182177099100. niltonpge@gmail.com
\end{abstract}

RESUMO

Considerando que a Constituição Federal de 1988 impõe, ao Ministério Público, o exercício da atividade de controle externo da ação policial (artigo129, VII), o artigo pretende investigar se a instituição possui a aptidão institucional para realizar investigações "efetivas" a respeito de casos que envolvam o uso potencialmente abusivo da força por agentes oficiais do Estado. O conceito de "investigação efetiva" é construído pela jurisprudência da Corte Europeia de Direitos Humanos que extrai, dos direitos à vida e à salvaguarda contra tratamentos desumanos ou degradantes, obrigações procedimentais a serem observadas pelos Estados signatários da Convenção Europeia de Direitos Humanos, com vistas à prevenção e investigação de eventuais atos que envolvam abuso de poder estatal. A investigação criminal efetiva é, portanto, um instrumento de proteção dos direitos humanos. Após abordar os parâmetros internacionais, o artigo analisa as atribuições constitucionais do Ministério Público e o regime jurídico-funcional sui generis que ele detém em relação à atividade policial. Este regime jurídico assegura-lhe autonomia jurídica e operacional para que possa atuar no âmbito do sistema de justiça criminal e para que possa realizar, enquanto instituição de police oversight, investigações efetivas de casos que envolvam potencial uso abusivo da força por agentes oficiais do Estado.

Palavras-chave: Controle externo da atividade policial. Ministério Público. Investigação. Corte Europeia de Direitos Humanos. Sistema de justiça criminal.

THE BRAZILIAN PUBLIC PROSECUTION'S OFFICE AS AN INSTITUTION OF POLICE OVERSIGHT: LAW ENFORCEMENT OVERSIGHT, HUMAN RIGHTS AND EFFECTIVE CRIMINAL INVESTIGATIONS

ABSTRACT

According to the Brazilian Constitution, the Public Prosecution Office is an institution of police oversight. Considering this, the paper investigates whether it has the institutional capacity to carry out "effective" criminal investigations on cases involving potential abuse of force by State officials. The concept of "effective investigation is built up by the European Court of Human Rights' case law and, it relates to the rights of life and protection against cruel and inhuman or degrading treatment. According to the European Court, the European nations must comply to procedural obligations in order to investigate cases of police abuse. Effective criminal investigations are, therefore, an instrument for the enforcement of basic human rights. After discussing the European standards, the paper analyzes the constitutional framework of the Brazilian Public Prosecution Office's and its link to legal regime of police activity. This regime grants the Brazilian Public Prosecution Office the necessary autonomy to engage on effective criminal investigations regarding cases involving potential abuse of force by State officials.

Keywords: Police oversight. Brazilian Public Prosecution Service. Criminal investigation. European Court of Human Rights. Criminal justice system.

1 Introdução. 2 A Jurisprudência da CorEDH: Características Institucionais Básicas de uma Instituição de Police Oversight. 3 O Modelo Brasileiro: Uma Relação Funcional Sui Generis Entre o Ministério Público e a Atividade Policial. 4 A Autonomia do Ministério Público para a Condução de Investigações Criminais. 5 Conclusão. 6 Referências. 


\section{INTRODUÇÃO}

Em um Estado de Direito, seus agentes oficiais ${ }^{1}$ são autorizados a, em determinadas situações, empregar a força física para o alcance de objetivos legítimos. ${ }^{2}$ A expressão "uso da força corresponde ao emprego de meios físicos que possam ferir uma pessoa ou provocar danos a um bem. Este uso da força, contudo, pode ser ilegal (unlawfull) ou excessivo (excessive). Será classificado como ilegal quando o seu emprego violar as regras internas daquele determinado Estado e será excessivo quando, apesar de inicialmente legítimo, passar a ser empregado, posteriormente, de forma desnecessária ou desproporcional (ONU, 2017). ${ }^{34}$

Ao interpretar os artigos 20 e 3ㅇ da Convenção Europeia de Direitos Humanos (ConEDH), ${ }^{5}$ a Corte Europeia de Direitos Humanos (CorEDH) estabeleceu o conceito de "investigação efetiva" para casos em que o uso da força, por agentes oficiais do Estado, tenha provocado a morte de um indivíduo ou possíveis lesões à sua integridade física.

Segundo a CorEDH, as obrigações decorrentes destas normas detêm natureza dúplice. Enquanto obrigações de caráter material, dizem respeito ao estabelecimento, por exemplo, de protocolos de atuação policial e a garantia de instalações de detenção adequadas. Já enquanto obrigações de caráter procedimental, condicionam os Estados a instituírem mecanismos investigativos aptos à elucidação de possíveis casos de abusos cometidos por agentes oficiais do Estado (BYRNE; PRIESTLEY, 2015). Essas obrigações procedimentais, segundo a corte, consubstanciam medidas de police oversight, conceito que, no Brasil, corresponde, genericamente, aos mecanismos de controle da atividade policial em busca de sua accountabiliy (ÁVILA, 2016a, p. 446).

\footnotetext{
1 A expressão "agentes oficiais do Estado" corresponde ao conjunto de agentes públicos que compõe agências policiais e quaisquer outras que exerçam atividades assemelhadas, por exemplo, outros órgãos investigativos ou de inteligência (CORTE..., 2011).

2 O artigo 144, caput, da Constituição da República Federativa do Brasil (CRFB/88), prevê que "A segurança pública, dever do Estado, direito e responsabilidade de todos, é exercida para a preservação da ordem pública e da incolumidade das pessoas e do patrimônio" (BRASIL, 1988).

3 O termo "uso arbitrário" da força (arbitrary use of force) é composto pelas espécies uso ilegal e uso excessivo da força. De acordo com o United Nations Office on Drugs and Crime (ONU, 2017), a expressão "uso da força" (use of force) significa o emprego de meios físicos que podem ferir uma pessoa ou causar dano a uma propriedade. $O$ uso da força por organismos policiais é disciplinado, internacionalmente, pelo Code of Conduct for Law Enforcement Officials (ONU, 1979) e pelos Basic Principles on the Use of Force and Firearms by Law Enforcement Officials (ONU, 1990).

4 A necessidade de investigação e punição de desvios de conduta cometidos por agentes oficiais do Estado, enquanto instrumento de preservação de Direitos Humanos, também é perspectiva consolidada no regime de Justiça de Transição. Nesse sentido: "O objetivo da justiça transicional implica em processar os perpetradores, revelar a verdade sobre crimes passados, fornecer reparações às vítimas, reformar as instituições perpetradoras de abuso e promover a reconciliação. 0 que foi mencionado anteriormente exige um conjunto inclusivo de estratégias formuladas para enfrentar o passado assim como para olhar o futuro a fim de evitar o reaparecimento do conflito e das violações. Considerando que, com frequência, as estratégias da justiça transicional são arquitetadas em contextos nos quais a paz é frágil ou os perpetradores conservam um poder real, deve-se equilibrar cuidadosamente as exigências da justiça e a realidade do que pode ser efetuado a curto, médio e longo prazo" (VAN ZYL, 2011, 47).

5 Estes dispositivos constituem, segundo a CorEDH, o "núcleo essencial" da ConEDH, ao preverem os direitos à vida e à salvaguarda contra tratamentos desumanos ou degradantes.
} 


\section{Democracia}

Investigação "efetiva", segundo a CorEDH, portanto, é medida de salvaguarda de direitos humanos e deve ser composta pelos seguintes vetores: (i) independência; (ii) adequação; (iii) prontidão; (iv) escrutínio público; e (v) participação da vítima. ${ }^{6}$

Considerando a íntima conexão entre a salvaguarda dos direitos humanos e a realização de "investigações efetivas" a respeito da possível utilização excessiva de violência por agentes oficiais do Estado, passa-se ao objetivo do presente artigo. Com ele, avaliaremos se o Ministério Público, enquanto instituição constitucionalmente legitimada ao controle externo da atividade policial (artigo 129, VII da CRFB/88 (BRASIL, 1988), detém as características institucionais necessárias à realização de "investigações efetivas" relacionadas ao uso de força, eventualmente ilegal ou excessiva, por agentes oficiais do Estado.

Para tanto, analisaremos, em primeiro lugar, as principais características que uma instituição voltada ao exercício do police oversight deve assumir, de modo a exercer atividade investigatória a respeito de fatos desta natureza. Essas características serão construídas com base nos vetores jurisprudenciais estabelecidos pela CorEDH, supraindicados. ${ }^{7}$

Em seguida, analisaremos como a Constituição Federal de 1988 estrutura o sistema brasileiro de controle da atividade policial e, especificamente, qual é o papel exercido pelo Ministério Público no âmbito deste sistema. Mostraremos que os seus princípios reitores e características institucionais o tornam a agência vocacionada, por excelência, ao exercício do police oversight. Abordaremos, ainda, como a jurisprudência do Supremo Tribunal Federal (STF, 2015), ao consagrar a iniciativa autônoma do Parquet para a investigação criminal, ratifica esta sua condição, consoante decidido no julgamento do Recurso Extraordinário com repercussão geral número 593.727 (RE 593.727).

\section{A JURISPRUDÊNCIA DA COREDH: CARACTERÍSTICAS INSTITUCIONAIS BÁSI- CAS DE UMA INSTITUIÇÃO DE POLICE OVERSIGHT}

Dentre os vetores que compõem o conceito de "investigação efetiva", três deles estão diretamente relacionados à modelagem institucional dos órgãos encarregados desta tarefa. São eles: (i) independência; (ii) adequação; e (iii) prontidão. Estes vetores serão apresentados a partir de casos julgados pela CorEDH.

\footnotetext{
6 Ao analisar os vetores desenvolvidos jurisprudencialmente pela COrEDH, o Comissário Europeu para os Direitos Humanos afirma: "An independent and effective police complaints system is of fundamental importance for the operation of a democratic and accountable police service. Independent and effective determination of complaints enhances public trust and confidence in the police and ensures that there is no impunity for misconduct or ill-treatment. A complaints system must be capable of dealing appropriately and proportionately with a broad range of allegations against the police in accordance with the seriousness of the complainant's grievance and the implications for the officer complained against. A police complaints system should be understandable, open and accessible, and have positive regard to and understanding of issues of gender, race, ethnicity, religion, belief, sexual orientation, gender identity, disability and age. It should be efficient and properly resourced, and contribute to the development of a caring culture in the delivery of policing services" (CONSELHO DA EUROPA, 2009, p. 3).

7 A análise dos parâmetros estabelecidos pelas cortes internacionais de justiça e as consequências práticas advindas da condenação brasileira no caso Damião Ximenes, são avaliadas por Francischetto e Aquino (2018).
} 


\section{Investigação independente:}

No início dos anos 90 do século 20, a população de Bucareste organizou uma série de protestos contra o governo provisório romeno formado após a queda de Nicolae Ceauşescu. Nos meses subsequentes, houve aumento da repressão contra os manifestantes e, entre 13 e 15 de junho de 1990, foram registrados graves casos de violência policial contra a população.

Nos anos seguintes, diversas investigações criminais foram conduzidas e, finalmente, direcionadas à promotoria militar romena. Não houve, contudo, a responsabilização criminal dos suspeitos até que, finalmente, em 17 de junho de 2009, a promotoria, junto a Corte Superior de Cassação, decidiu não oferecer denúncias criminais em relação aos casos registrados entre 13 e 15 de junho de 1989 (CORTE..., 2014, p. 3-27). ${ }^{8}$

Vítimas da violência oficial apresentaram o caso à CorEDH que, ao julgá-lo, reiterou a existência de obrigações instrumentais associadas às normas previstas nos $2 \circ$ e 30 da ConE$\mathrm{DH}$, de modo que "the provisions of Articles 2 and 3 require by implication that there should be some form of effective official investigation" para os casos de uso excessivo ou ilegal da força policial. ${ }^{9}$

Considerando, no entanto, que as investigações foram lentas, ineficientes e, além disso, conduzidas em grande medida por militares romenos - muitos deles vinculados hierarquicamente a suspeitos de haverem cometido os crimes - a CorEDH entendeu que obrigações procedimentais decorrentes dos artigos $2 \circ$ e 3 da ConEDH haviam sido violadas.

Um dos pontos levantados pela CorEDH foi, justamente, o de que a condução das investigações por agentes vinculados hierarquicamente aos suspeitos, não poderia ser qualificada de independente. Segundo a CorEDH, independente é a investigação conduzida por instituição que não detenha conexões orgânicas com as agências ou autoridades oficiais investigadas. $^{10}$

\footnotetext{
Alguns casos ainda pendiam de julgamento mesmo durante o julgamento do caso pela CorEDH.

9 Ao abordar o conteúdo normativo destes dispositivos, a CorEDH asseverou: "It reiterates that Article 3, like Article 2, must be regarded as one of the most fundamental provisions of the Convention and as enshrining core values of the democratic societies making up the Council of Europe (see Soering v. the United Kingdom, 7 July 1989, § 88, Series A no. 161). In contrast to the other provisions in the Convention, it is cast in absolute terms, without exception or proviso, or the possibility of derogation under Article 15 of the Convention (see Al-Skeini and Others, cited above, § 162)." A CorEDH afirmou, ainda, que a salvaguarda destes princípios fundamentais não seria possível se obrigações de natureza instrumental não fossem impostas aos países submetidos à sua jurisdição. Neste sentido: "The general legal prohibition of arbitrary killing and torture and inhuman or degrading treatment or punishment by agents of the State would be ineffective in practice if there existed no procedure either for reviewing the lawfulness of the use of lethal force by State authorities, or for investigating arbitrary killings and allegations of ill-treatment of persons held by them (see Al-Skeini and Others, cited above, § 163, and El-Masri, cited above, § 182)." (CORTE..., 2014, p. 53-54).

${ }^{10}$ Segundo a COrEDH: "Generally speaking, for an investigation to be effective, the persons responsible for carrying it out must be independent from those targeted by it. This means not only a lack of hierarchical or institutional connection but also a practical independence (see Nachova and Others, cited above, § 110, and Halat v. Turkey, no. 23607/08, § 51, 8 November 2011)." (CORTE..., 2014, p. 54).
} 


\section{Democracia}

\section{Investigação adequada}

Zeni Aksoy alegou ter sido preso e torturado ${ }^{11}$ por agentes da polícia turca após ser apontado como suposto membro de um grupo terrorista. Ele nunca seria acusado formalmente por estes supostos crimes, tampouco nenhuma investigação oficial do Estado turco seria conduzida para a apuração dos possíveis atos de tortura contra ele praticados, pois, em 16 de abril de 1994, Aksoy foi assassinado. De acordo com seus representantes legais, este homicídio seria o estágio final de uma série de ameaças perpetradas contra Aksoy, decorrentes de sua insistência em apresentar o caso às instâncias internacionais.

Ao julgar o caso, a COrEDH interpretou em conjunto os artigos 3ㅇ e 13 da ConEDH, de modo que este último imporia, aos Estados-parte, "without prejudice to any other remedy available under the domestic system, an obligation on States to carry out a thorough and effective investigation of incidents of torture" (CORTE..., 1996, p. 25-26).

Diante da inércia das autoridades em investigar as fundadas alegações de tortura apresentadas por Zeni Aksoy, a CorEDH condenou o Estado turco, ao considerar que a ConEDH obriga os Estados-parte a promoverem investigações adequadas caso sejam confrontados com possíveis atos de violência oficial. ${ }^{12}$

\section{Investigação imediata}

Şükran Aydin é uma cidadã turca de origem curda. De acordo com os fatos analisados pela CorEDH, ela e sua família foram interrogadoa por agentes oficiais do Estado turco, em 29/6/1993, por supostas ligações com grupos terroristas. Segundo Aydin, ela e sua família foram detidos à força pela polícia, momento em que ela, inclusive, foi torturada e submetida à violência sexual.

Ao final do julgamento, a CorEDH reconheceu que a ineficácia das investigações conduzidas pelas autoridades turcas violaria o artigo 30 da ConEDH. ${ }^{13}$ Ao fazê-lo, a CorEDH entendeu que as autoridades turcas falharam ao não adotarem as providências investigativas assim que tomaram ciências das alegações das vítimas. Para que uma investigação pronta

\footnotetext{
11 Segundo a CorEDH: "The applicant complained of having been ill-treated in different ways. He claimed to have been kept blindfolded during interrogation, which caused disorientation; to have been suspended from his arms, which were tied together behind his back ("Palestinian hanging"); to have been given electric shocks, which were exacerbated by throwing water over him; and to have been subjected to beatings, slapping and verbal abuse. He referred to medical evidence from Dicle University Medical Faculty which showed that he was suffering from a bilateral brachial plexus injury at the time of his admission to hospital (see paragraph 19 above). This injury was consistent with Palestinian hanging." (CORTE..., 1996, p. 16).

12 "Accordingly, as regards Article 13 (artigo 13), where an individual has an arguable claim that he has been tortured by agents of the State, the notion of an "effective remedy" entails, in addition to the payment of compensation where appropriate, a thorough and effective investigation capable of leading to the identification and punishment of those responsible and including effective access for the complainant to the investigatory procedure. It is true that no express provision exists in the Convention such as can be found in Article 12 of the 1984 United Nations Convention against Torture and Other Cruel, Inhuman or Degrading Treatment or Punishment, which imposes a duty to proceed to a "prompt and impartial" investigation whenever there is a reasonable ground to believe that an act of torture has been committed. However, in the Court's view, such a requirement is implicit in the notion of an "effective remedy" under Article 13" (CORTE..., 1996, p. 26).

${ }^{13}$ A respeito das investigações conduzidas pelas autoridades turcas, a CorEDH afirmou: "In the view of the Court, this cannot justify the serious defects and inertia which characterised the crucial phase immediately following receipt of the complaint. The public prosecutor had at that stage the legal means to act promptly and gather all necessary evidence including, as appropriate, psychological and behavioural evidence; nor can the decision to suspend the investigation on account of the applicant's absence be justified given the gravity of the offence under investigation." (CORTE..., 1997).
} 
(imediata) ocorra, portanto, a instituição por ela responsável deve possuir mecanismos que Ihe possibilitem o imediato contato com a notícia-crime relacionada a possíveis abusos cometidos por agentes oficiais do Estado. Ao avaliar este vetor, a CorEDH entendeu que o Estado turco investigou com "sérios defeitos e inércia" o caso envolvendo as violações aos Direitos Humanos - supostamente cometidas por seus agentes oficiais - contra a senhora Şükran Aydin (CORTE..., 1997).

Verificadas as características institucionais básicas extraídas dos vetores estabelecidos pela CorEDH, passa-se à análise do sistema constitucional de controle da atividade policial brasileiro e, mais especificamente, das atribuições do Ministério Público enquanto instituição de police oversight.

\section{O MODELO BRASILEIRO: UMA RELAÇÃO FUNCIONAL SUI GENERIS ENTRE O MINISTÉRIO PÚBLICO E A ATIVIDADE POLICIAL ${ }^{14}$}

Por deterem natureza jurídica de órgãos públicos, as polícias submetem-se aos controles internos da Administração Pública - federal ou estadual - a que se encontram vinculadas (ÁVILA, 2016a, p. 460). A estes órgãos aplica-se o regime jurídico de Direito Público, incidindo, sobre eles, o princípio hierárquico.

Em última instância, portanto, as instituições policiais prestam contas à chefia do Poder Executivo a que se encontram vinculadas (Presidência da República ou Governadorias dos Estados, a depender do caso), e a instâncias administrativas integradas por representantes democraticamente eleitos, a quem compete o estabelecimento de políticas públicas de segurança. Os controles internos voltam-se à análise, principalmente, das repercussões correicionais relacionadas a eventuais atos ilícitos cometidos pelos agentes oficiais.

No que diz respeito à atividade policial, contudo, a própria Constituição Federal de 1988 (BRASIL, 1988) entende que a existência de controles internos é insuficiente, motivo pelo qual outorga, ao Ministério Público, a condução do controle externo da atividade policial (129, VII da CRFB/88).

Neste sentido, a Lei Orgânica do Ministério Público da União (Lompu ou LC 75/93) aplicável aos demais ramos do Ministério Público brasileiro, nos termos do artigo 80 da Lei 8625/93 - apresenta os objetivos a serem alcançados mediante o exercício do controle externo. O artigo 3 da LC 75/93 prevê que essa tarefa terá como objetivo, dentre outros, o "respeito aos fundamentos do Estado Democrático de Direito, aos objetivos da República Federativa do Brasil", bem como aos "direitos assegurados na Constituição Federal". Ainda, de acordo com a LC 75/93, o exercício do controle externo da atividade policial deverá buscar a "prevenção e a correção de ilegalidade ou de abuso de poder" (artigo 3o, alínea "c"). Controles internos e externos, neste contexto, complementam-se, mas devem ser exercidos sob perspectivas distintas.

\footnotetext{
${ }^{14}$ Para uma análise do modelo institucional da Polícia Militar brasileira, seu desenvolvimento histórico e métodos de trabalho, ver: SILVA et al. 2017.
} 
A correta delimitação do alcance e da extensão da norma prevista no artigo 129, VII da CRFB/88 (BRASIL, 1988), todavia, deve ser alcançada mediante uma interpretação sistêmica de outras normas constitucionais. Analisadas em conjunto, estas normas delineiam as relações funcionais que existem entre o Ministério Público e a atividade policial. O conteúdo normativo da expressão "controle externo da atividade policial", portanto, é ainda mais abrangente.

A primeira característica do Ministério Público, extraída da CRFB/88, é a que lhe assegura independência política ante os demais Poderes da República. ${ }^{15}$ Esta autonomia pode ser encarada sob distintas projeções: administrativo-orçamentária (artigo 127, parágrafos 2ㅇ e 3으 da CRFB/88). ${ }^{16}$ Este regime jurídico proporciona, ao Ministério Público, a neutralidade política que é inerente às suas atividades. ${ }^{17}$ Ele, nesse contexto, não detém conexões orgânicas com nenhum dos Poderes da República, e pauta a sua atuação, unicamente, a partir de critérios técnico-jurídicos. A reforçar a sua posição de independência diante dos demais Poderes, a CRFB/88 assegura a seus membros independência funcional (artigo 127, parágrafo 10 da CRFB/88).

Outra norma constitucional que serve à modelagem institucional do Ministério Público é a extraída do artigo $129, \mathrm{I}$, da CRFB/88, que Ihe atribui a titularidade exclusiva da ação penal pública. Isso significa que, ao promover a persecução penal em Juízo, a instituição atua enquanto órgão de Estado, e exerce, por conta disso, parcela de soberania no âmbito do sistema de justiça criminal (MAZZILLI, 2002, p. 464). Assim, na qualidade de titular da ação penal pública, o Ministério Público é o destinatário de qualquer investigação, ainda que realizada por outro órgão estatal, cujos objetos detenham possível repercussão criminal. Por ser a investigação uma atividade instrumental em relação às funções do Ministério Público - responsável exclusivo pela opinião delitiva do Estado -, aos demais órgãos que realizem investigações é vedado que lhe seja subtraído o conhecimento de notícias-crime (ÁVILA, 2016a, p, 588).

Outros importantes atributos constitucionais do Ministério Público dizem respeito à sua legitimidade para requisitar junto aos organismos policiais a instauração de inquéritos policiais e a realização de diligências investigativas. "Requisitar", em termos técnicos, significa "ordem administrativa", cujo cumprimento não pode, como regra, ser negado (ÁVILA, 2016a).

Analisadas essas normas em conjunto, verifica-se que o Ministério Público compartilha um regime jurídico diferenciado em relação às instituições policiais, regime este que é composto pelas normas constitucionais que especificam as suas atribuições. A partir daí, pode-se

\footnotetext{
${ }^{15}$ Até 1988, o Ministério Público não detinha o grau de autonomia de que hoje dispõe. Exemplo disso, é que foi a CRFB/88 a responsável por proibir, ao Ministério Público, "a representação judicial e a consultoria jurídica de entidades públicas" (artigo 129, IX da CRFB/88). Por outro lado, um resquício da vinculação do MPF à União encontra-se no artigo 128, parágrafo 1을 da CRFB/88, que prevê a nomeação do Procurador-Geral da República pelo presidente da República, após escrutínio pelo Senado Federal. A escolha da chefia da instituição, em âmbito federal, não replica a norma voltada aos Ministérios Públicos dos Estados, cujos Procuradores-Gerais são nomeados pelos governadores a partir de lista tríplice elaborada pelos membros das respectivas carreiras (artigo 128, parágrafo 3ㅇ da CRFB/88).

${ }^{16}$ Ainda que, formalmente, o Ministério Público não integre nenhum dos Poderes da República (artigo 20 da CRFB/88), seu desenho institucional assegura-Ihe regime jurídico de magistratura, de modo que, segundo Mazzilli (2002, p. 464), a CRFB/88 Ihe consagrou um "elevado status constitucional". Para uma análise aprofundada do regime jurídico do Ministério Público - e das consequências práticas destes regime -, ver GARCIA, 2017

${ }^{17}$ As prerrogativas e vedações constitucionais, previstas no artigo 128, parágrafo 5o, I e II da CRFB/88, também representam importante instrumento para o distanciamento do Ministério Público das atividades político-partidárias.
} 
afirmar que o núcleo essencial desse regime jurídico sui generis é constituído pela autonomia funcional que o Ministério Público detém para iniciar, impulsionar e - se entender inviável o exercício da ação penal - encerrar, por autoridade própria, a fase investigativa da persecução penal. É este regime jurídico especial que lhe permite atuar com independência no âmbito do sistema de justiça criminal.

Classifica-se esse regime de sui generis porque, apesar de o conjunto de normas analisado autorizar o Ministério Público a conformar a atividade policial, entre ambas as instituições não há relações hierárquicas, conforme já abordado. Ainda assim, é ele - enquanto titular exclusivo da ação penal pública e controlador externo da atividade policial - o responsável por formular juízo definitivo a respeito do resultado da investigação. Essa percepção é reforçada considerando que, às polícias, é legalmente vedada a disposição do inquérito policial. Esse regime é reforçado pela Constituição Federal e teve sua gênese no próprio Código de Processo Penal (CPP) editado em 1941 (BRASIL, 1941), cujas normas, nesse aspecto, foram recepcionadas pela ordem constitucional de 1988. O artigo 5, II do CPP/1941, nesse contexto, reforça o poder requisitório (de iniciativa) do Ministério Público ante a polícia. Já o artigo 17 do CPP/1941 prevê que "a autoridade policial não poderá mandar arquivar autos de inquérito", o que, combinado com os artigos 16 e 28 do CPP/1941, demonstra incumbir unicamente ao Ministério Público, decidir o momento do encerramento das investigações. Seu poder de iniciativa, para o inquérito policial, portanto, é compartilhado com a polícia, mas o poder de disposição (arquivamento) Ihe é exclusivo.

Essa posição de independência, no entanto - para que atinja os parâmetros estabelecidos pela CorEDH - precisar ser "efetiva" e "prática", o que pressupõe, ainda, a sua autonomia operacional para atuar.

\section{A AUTONOMIA DO MINISTÉRIO PÚBLICO PARA A CONDUÇÃO DE INVESTIGAÇÕES CRIMINAIS}

Conforme visto anteriormente, o conceito de "investigação efetiva" é composto pelos vetores independência, adequação e prontidão. Analisados em conjunto estes vetores, conclui-se que a instituição responsável pelo police oversight deva possuir autonomia orgânica, jurídica e operacional para conduzir as investigações sobre possíveis casos de violência cometidos por agentes oficiais do Estado. Esta instituição, em resumo, deve atuar de modo que "les investigations soient indépendantes de celles impliquées dans les événements, en excluant tout lien hiérarchique ou institutionnel et en exigeant également une indépendance pratique" (CORTE..., 2011, p. 7).

Consoante supra, o regime jurídico atribuído pela CRFB/88 ao Ministério Público, assegura-Ihe autonomia em relação ao Poder Executivo, a quem as instituições policiais encontram-se, organicamente, vinculadas. Este mesmo regime jurídico permite ao Ministério Público atuar com independência jurídica em relação às polícias, uma vez que é ele o responsável pela formação da opinião delitiva do Estado.

A questão da independência operacional (capacidade para conduzir investigações criminais autonomamente), no entanto, sempre foi controvertida. O tema envolve duas posições antagônicas. 
Os que são contrários à autonomia investigativa do Ministério Público entendem que a CRFB/88 teria outorgado, às polícias civil e federal, o monopólio da investigação criminal. Essa visão passa por uma interpretação restritiva do artigo $144 \S 1$ 1ㄴ, IV, e da expressão "polícia judiciária".

Os que defendem a autonomia investigativa do Ministério Público afirmam, por outro lado, que a atividade de polícia judiciária não se confunde, necessariamente, com investigação criminal, cujo conceito seria mais amplo. Nesse contexto, não haveria de se falar em qualquer "monopólio" outorgado às polícias. ${ }^{18}$ Ainda que se pudesse falar em exclusividade - argumentam os defensores da autonomia do Ministério Público -, ela não poderia ser oposta ao Ministério Público, cujo regime jurídico é definido não pelo artigo 144 da CRFB/88, mas pelos artigos 127 a 129 da CRFB/88. Nesse contexto, a sua autonomia investigativa seria extraída de sua condição de titular exclusivo da ação penal pública (artigo 129, I da CRFB/88), controlador externo da atividade policial (artigo 129, VII da CRFB/88) e de sua legitimidade para instruir os "procedimentos administrativos de sua competência" (artigo 129, VI da CRFB/88).

Esta controvérsia ${ }^{19}$ somente foi solucionada em definitivo com o julgamento pelo STF, em 2015, do julgamento do Recurso Extraordinário n. 593.727, afetado ao regime da repercussão geral. ${ }^{20} \mathrm{Na}$ oportunidade, o recorrente sustentava que o Ministério Público haveria extrapolado as suas atribuições ao conduzir, diretamente, a investigação criminal, que resultaria na denúncia contra si. Esta tese acabou sendo rechaçada pelo plenário do Supremo Tribunal Federal.

\footnotetext{
${ }^{18}$ O STF, em julgamento ocorrido em 30/4/1997, já havia afirmado que a investigação criminal não seria monopólio das polícias judiciárias. É bem verdade que essa afirmação havia sido emitida em caráter de obter dictum e que, na época, o STF tinha reconhecido a possibilidade de o juiz realizar, por si só, atos investigativos (ADI 1517-6). Esta decisão, contudo, foi posteriormente revista mediante a afirmação de que o sistema de justiça criminal, desenhado pela CRFB/88, deteria natureza acusatória, em que as funções de acusação e julgamento não se confundiriam (ADI 1570). Filiamo-nos à corrente de que as atividades de "polícia judiciária" não se confundem com a investigação criminal e de que o Ministério Público detém autonomia para, por conta própria, realizar atos de investigação criminal.

${ }^{19}$ Antes mesmo de o RE 593.727 ser decidido, o debate a respeito da titularidade da investigação criminal já havia ocorrido no âmbito do próprio STF. Se, por meio da Ação Direta de Inconstitucionalidade n. 1.570, o STF decidiu ser inconstitucional à realização, diretamente pelo Poder Judiciário, de diligências investigativas de natureza criminal, a controvérsia a respeito da autonomia do Ministério Público para promovê-las encontrava-se latente. Se, por um lado, o Ministro Ayres Britto afirmou a sua "absoluta convicção" de que o Ministério Público poderia investigar, o ministro Nelson Jobim afirmou ser "absolutamente contrário", "às atividades investigatórias do Ministério Público" - ainda que com a seguinte ressalva: "desde que as mesmas atividades sejam dadas à defesa" (STF, 2004).

${ }^{20}$ A tese fixada pela Corte foi a seguinte: "O Ministério Público dispõe de competência para promover, por autoridade própria, e por prazo razoável, investigações de natureza penal, desde que respeitados os direitos e garantias que assistem a qualquer indiciado ou a qualquer pessoa sob investigação do Estado, observadas, sempre, por seus agentes, as hipóteses de reserva constitucional de jurisdição e, também, as prerrogativas profissionais de que se acham investidos, em nosso País, os Advogados (Lei 8.906/94, artigo 7o, notadamente os incisos I, II, III, XI, XIII, XIV e XIX), sem prejuízo da possibilidade - sempre presente no Estado democrático de Direito - do permanente controle jurisdicional dos atos, necessariamente documentados (Súmula Vinculante 14), praticados pelos membros dessa instituição" (STF, 2015).
} 
Ao (re)afirmar os poderes investigatórios autônomos do Ministério Público, o STF os extraiu, justamente, do regime jurídico-constitucional do Parquet. ${ }^{21} \mathrm{Em}$ seu voto, o ministro Celso de Mello demonstrou preocupação em assegurar, ao Ministério Público, autonomia operacional para que, por autoridade própria, pudesse investigar criminalmente casos que envolvessem a eventual utilização irregular da força por agentes oficiais do Estado. Para justificar o seu entendimento, ele utilizou o conjunto de dispositivos constitucionais anteriormente trabalhados, responsáveis por moldar o regime jurídico-funcional sui generis que o Ministério Público detém em relação à atividade policial. De acordo com ele:

Isso significa que a outorga de poderes explícitos, ao Ministério Público, tais como aqueles enunciados no artigo 129, incisos I, VI, VII, VIII e IX, da Lei Fundamental da República, supõe que se reconheça, ainda que por implicitude, aos membros dessa Instituição, a titularidade de meios destinados a viabilizar a adoção de medidas vocacionadas a conferir real efetividade às suas atribuições, permitindo, assim, que se confira efetividade aos fins constitucionalmente reconhecidos ao Ministério Público" (STF, 2015).

Verifica-se, portanto, que a possibilidade de o Ministério Público realizar, por conta própria, diligências investigativas criminais, diz respeito à sua posição institucional no sistema de justiça criminal e decorre tanto do regime jurídico, que lhe é próprio, quanto das interações recíprocas que estabelece com a atividade policial.

Por fim, um registro importante. Ainda que o presente trabalho diga respeito, unicamente, à investigação de eventuais desvios de conduta policiais, defendemos que o Ministério Público detém poder de iniciativa autônomo em sentido amplo para a investigação de crimes de qualquer natureza. Ainda que, em regra, as investigações criminais devam ocorrer em parceria com as polícias, isso não significa que o Ministério Público não detenha legitimidade para - caso entenda necessário - realizar diligências investigatórias por conta própria. Eventual dependência material ou operacional, em relação às polícias, subverteria o seu relevante papel no âmbito do sistema de justiça criminal brasileiro.

\footnotetext{
${ }^{21}$ Para fins do presente artigo, são relevantes as afirmações feitas, em plenário, pelo ministro Celso de Mello: "Quando o Supremo Tribunal Federal, em sessão plenária, reuniu-se, em 1971, para apreciar o RHC 48.728/SP, interposto pelo Delegado Sérgio Fernando Paranhos Fleury, o eminente Relator da causa, o saudoso Ministro LUIZ GALLOTTI, antes de examinar a questão pertinente à alegada impossibilidade jurídica da unipersonalização da investigação e da acusação penais, cuja suscitação fora motivada pelo ominoso episódio do "Esquadrão da Morte", pôde lançar uma grave advertência sobre o alto significado da decisão a ser então tomada por esta Corte, enfatizando, à semelhança do que também ocorre na espécie ora em análise, que se tratava de um daqueles casos emblemáticos em que o Supremo Tribunal Federal, ao proferir o seu julgamento, poderá ser, ele próprio, “julgado pela Nação" (RTJ 63/299, 312).

Ninguém ignora que a principal tese sustentada, perante esta Suprema Corte, pelo personagem-símbolo do "Esquadrão da Morte", consistia, precisamente, na alegação de que o órgão público incumbido de formular a acusação criminal estava juridicamente impedido de fazê-lo, porque também autor da investigação penal em que tal acusação se apoiava.

${ }^{E}$ SSa tese, como é de conhecimento geral, não prevaleceu nesta Suprema Corte, o que permitiu, num momento de franco e perigoso declínio das liberdades públicas em nosso país, então submetido a um regime de dominação castrense, que o Ministério Público paulista, por iniciativa do eminente Procurador de Justiça, doutor Hélio Pereira Bicudo, diretamente apoiado por dois ilustres promotores de Justiça, doutores José Sylvio Fonseca Tavares e Dirceu de Mello, promovesse as investigações criminais necessárias que culminaram na posterior formulação das pertinentes acusações penais, desestruturando, assim, aquela sinistra organização criminosa reunida, no Estado de São Paulo, sob a vergonhosa designação de "Esquadrão da Morte" (STF, 2015).
} 


\section{CONCLUSÃO}

A CRFB/88 assegura, ao Ministério Público, independência para atuar no âmbito do sistema de justiça criminal tanto na atividade de persecução penal quanto no exercício do police oversight. É a partir do seu regime jurídico-constitucional que se extrai uma relação funcional sui generis entre ele e a atividade policial. O núcleo essencial desta relação diz respeito à sua autonomia para iniciar, impulsionar e - se entender ser o caso - encerrar a atividade de investigação criminal (justificadamente, mediante arquivamento fundamentado).

Para além dessa autonomia jurídica, no entanto, o seu regime jurídico-constitucional Ihe assegura, ainda, autonomia operacional para atuar, o que abrange a sua legitimidade para realizar, por conta própria, atos de investigação criminal. Neste sentido, a decisão proferida pelo STF nos autos do Recurso Extraordinário número 593.727, é importante porque afasta a controvérsia que existia a respeito da autonomia operacional do Ministério Público.

Munido de ambos os feixes de sua autonomia (jurídica e operacional), o Ministério Público, enquanto instituição de police oversight, detém condições de realizar investigações "efetivas" - de acordo com os parâmetros estabelecidos pela CorEDH - a respeito de casos que lhe cheguem ao conhecimento e que envolvam a eventual utilização abusiva da coerção física por agentes oficiais do Estado.

\section{REFERÊNCIAS}

ÁVILA, Thiago André Pierobom de. Fundamentos de controle externo da atividade policial. Belo Horizonte: Editora D’Plácido, 2016 a.

ÁVILA, Thiago André Pierobom de. Investigação criminal: o controle externo de direção mediata pelo Ministério Público. Curitiba: Juruá, 2016b.

BRASIL. Constituição da República Federativa do Brasil de 1988. 1988. Disponível em: http://www.planalto.gov. br/ccivil_03/Constituicao/Constituicao.htm. Acesso em: 19 fev. 2019.

BRASIL. Decreto-Lei n. 3689 de 3 de outubro de 1941. 1941. Disponível em: http://www.planalto.gov.br/ccivil_03/decreto-lei/Del3689.htm. Acesso em: 19 fev. 2019.

BRASIL. Lei Complementar número 75 de 20 de maio de 1993. 1993. Disponível em: http://www.planalto.gov.br/ ccivil_03/leis/lcp/Lcp75.htm. Acesso em: 19 fev. 2019.

BYRNE, Jonny; PRIESTLEY, William. Police oversight mechanisms in the Council of Europe member states. França: Council of Europe Publishing, 2015. Disponível em: https://edoc.coe.int/en/international-law/7414-police-oversight-mechanisms-in-the-council-of-europe-member-states.html. Acesso em: 19 nov. 2018.

CONSELHO DA EUROPA. Opinion for the Comissioner for Human Rights concerning independent and effective determination of complaints against the police. 2009. Disponível em: https://rm.coe.int/opinion-of-the-commissioner-for-human-rights-thomas-hammarberg-concern/16806daa54. Acesso em: 16 fev. 2019.

CORTE EUROPEIA DE DIREITOS HUMANOS. Sentença caso Aksoy v Turkey. Julgado em 18 dez. 1996. Disponível em: https://hudoc.echr.coe.int/eng\#\{\%22fulltext\%22:[\%22aksoy\%20v\%20turkey\%22],\%22documentcollectionid2\%22:[\%22GRANDCHAMBER\%22,\%22CHAMBER\%22],\%22itemid\%22:[\%22001-58003\%22]\}. Acesso em: 19 fev. 2019.

CORTE EUROPEIA DE DIREITOS HUMANOS. Sentença caso Audin v Turkey. Julgado em: 25 set. 1997. Disponível em: https://hudoc.echr.coe.int/eng\#\{\%22fulltext\%22:[\%22aydin\%20v\%20turkey\%22],\%22documentcollectionid2\%22:[\%22GRANDCHAMBER\%22,\%22CHAMBER\%22],\%22itemid\%22:[\%22001-58371\%22]\}. Acesso em: 16 fev. 2019.

CORTE EUROPEIA DE DIREITOS HUMANOS. Sentença caso Halat v Turkey. Julgado em 8 nov. 2011. Disponível em: https://hudoc.echr.coe.int/eng\#\{\%22itemid\%22:[\%22001-107331\%22]\}. Aceso em: 16 fev. 2019. 
CORTE EUROPEIA DE DIREITOS HUMANOS. Sentença caso Ireland $v$ the United Kingdom. Julgado em 18 jan. 1978. Disponivel em: https://hudoc.echr.coe.int/eng\#\{22fulltext\%22:[\%22(\\%22IRELAND\%20V\%20THE\%20 UNITED\%20KINGDOM\\%22)\%22],\%22documentcollectionid2\%22:[\%22GRANDCHAMBER\%22,\%22CHAMBER\%22],\%22itemid\%22:[\%22001-57506\%22]\}. Acesso em: 19 fev. 2019.

CORTE EUROPEIA DE DIREITOS HUMANOS. Sentença caso Mocanu and others v Romania. Julgado em 17 set. 2014. Disponível em: https://hudoc.echr.coe.int/eng\#\{\%22fulltext\%22:[\%2210865/09\%22],\%22documentcollectionid2\%22:[\%22GRANDCHAMBER\%22,\%22CHAMBER\%22]\}. Acesso em: 15 fev. 2019.

FRANCISCHETTO, Gilsilene; AQUINO, Bruna. Os efeitos advindos da condenação do Brasil no caso Damião Ximenes Lopes na Corte Interamericana de Direitos Humanos por violação aos Direitos Humanos previstos no Pacto de San José da Costa Rica. Revista Direitos Humanos e Democracia, v. 6, n. 12, p. 67-84, 14 nov. 2018.

GARCIA, Emerson. Ministério Público: organização, atribuições e regime jurídico. 6. ed. São Paulo: Saraiva, 2017. GOLDSTEIN, Joseph. Police Discretion Not to Invoke the Criminal Process: Low-Visibility Decisions in the Administration of Justice. In: Yale Law School Legal Scholarship Repository. 1960. Disponível em: https://digitalcommons. law.yale.edu/cgi/viewcontent.cgi?article=3417\&context=fss_papers. Acesso em: 18 fev. 2019.

MAZZILLI, Hugo Nigro. A natureza das funções do Ministério Público e sua posição no processo penal. 2002. Disponível em: http://www.mazzilli.com.br/pages/artigos/naturezamp.pdf. Acesso em: 16 fev. 2019.

MAZZUOLI, Valerio de Oliveira. Direitos humanos na jurisprudência internacional. 1. ed. São Paulo: Método, 2019.

ONU. Organização das Nações Unidas. Basic Principles on the Use of Force and Firearms by Law Enforcement Officials. 1990. Disponível em: https://www.un.org/ruleoflaw/blog/document/basic-principles-on-the-use-of-force-and-firearms-by-law-enforcement-officials/. Acesso em: 26 jul. 2019.

ONU. Organização das Nações Unidas. Code of Conduct for Law Enforcement Officials. 1979. Disponível em: https://www.ohchr.org/EN/Professionallnterest/Pages/LawEnforcementOfficials.aspx. Acesso em: 26 jul. 2019.

ONU. Organização das Nações Unidas.. Resource book on the use of force and firearms in law enforcement. 2017. Disponível em: https://www.policinglaw.info/assets/downloads/UNODC_Use_Of_Force_and_Firearms_ Resource_Book.pdf. Acesso em: 25 jul. 2019.

RAMOS, André de Carvalho. Processo internacional dos direitos humanos. 6. ed. São Paulo: Saraiva, 2019

REIDY, Aisling. The prohibition of torture: A guide to the implementation of Article 3 of the European Convention on Human Rights. Alemanha: Council of Europe, 2003. Disponível em: https://rm.coe.int/168007ff4c. Acesso em: 15 fev. 2019.

ROTH-ARRIAZA, Naomi. Impunity and human rights in international law and practice. Nova lorque: Oxford University Press, 1995.

SILVA, Allan; SILVA, Luciano; NITÃO, Maria Ivonete; DA SILVA, Ivayr. O Brasil da polícia militar do Brasil: reflexões sobre a construção da (in)segurança pública no século 21. Revista Direitos Humanos e Democracia, v. 5, n. 10, p. 117-149, 31 out. 2017.

VAN ZYL, Paul. Promovendo a justiça transicional em sociedades pós-conflito. In: REÁTEGUI, Felix. Justiça de transição: manual para a América Latina. Brasília: Comissão de Anistia. 2011. p. 47-71. Disponível em: http://www. justica.gov.br/central-de-conteudo/anistia/anexos/jt-manual-para-america-latina-portugues.pdf. Acesso em: 18 fev. 2019.

STF. Supremo Tribunal Federal. Ação Direta de Inconstitucionalidade número 1570/DF. Rel. min. Maurício Corrêa. Julgado em 12 fev. 2004. Publicado em 22 out. 2004. Disponível em: http://portal.stf.jus.br/processos/detaIhe.asp?incidente=1662827. Acesso em: 26 jul. 2019.

STF. Supremo Tribunal Federal. Ação Direta de Inconstitucionalidade número 4693/BA. Rel. min. Alexandre de Moraes. Tribunal Pleno. Julgado em 11 out. 2018. Publicado em 30 out. 2018. Disponível em: http://portal.stf. jus.br/processos/detalhe.asp?incidente=4173868. Acesso em: 19 fev. 2019.

STF. Supremo Tribunal Federal. Recurso Extraordinário número 593.727/MG. Rel. min. Gilmar Mendes. Tribunal Pleno. Julgado em 14 maio 2015. Publicado em 8 set. 2015. Disponível em: http://portal.stf.jus.br/processos/ detalhe.asp?incidente=2641697. Acesso em: 19 fev. 2019. 